\title{
Adenovirus-mediated interferon- $\beta$ gene transfer inhibits angiogenesis in and progression of orthotopic tumors of human prostate cancer cells in nude mice
}

\author{
JUWON LEE ${ }^{1}$, AMY WANG ${ }^{2}$, QIANDE HU ${ }^{2}$, SHAN LU $^{3}$ and ZHONGYUN DONG ${ }^{2}$ \\ ${ }^{1}$ Genome Research Institute, ${ }^{2}$ Department of Internal Medicine, ${ }^{3}$ Department of Pathology and \\ Laboratory Medicine, University of Cincinnati College of Medicine, Cincinnati, OH, USA
}

Received June 22, 2006; Accepted August 14, 2006

\begin{abstract}
Interferon (IFN)- $B$ is a multifunctional cytokine. Our previous studies revealed that intratumoral transfer of the murine interferon (IFN)- $\beta$ gene inhibited the growth of human and mouse prostate cancer cells in mice. Since IFN- $\beta$ activity is species-restricted, we investigated the efficacy and mechanisms of forced expression of human IFN- $\beta$ in suppressing the growth of human prostate cancer cells in mice. Orthotopic tumors of PC-3MM2 human prostate cancer cells were forced to express human IFN- $\beta$ by intratumoral injection of an adenoviral vector (AdhIFN-B). Tumor growth and survival of tumor-bearing mice were determined. Cell proliferation and apoptosis were evaluated by immunohistochemistry (IHC) and terminal deoxynucleotidyl transferasemediated dUTP nick-end labeling (TUNEL). Angiogenesis and angiogenic molecule expression were evaluated by IHC and quantitative real-time reverse-transcriptional PCR (qRT-PCR). We found that forced expression of human IFN- $\beta$ inhibited tumor growth in a dose-dependent manner. An injection of $2 \times 10^{9}$ PFU (plaque-forming units) of AdhIFN- $\beta$ retarded tumor growth by $90 \%$ and prolonged the survival of tumorbearing mice. Control tumors contained more proliferating cells $\left(\mathrm{PCNA}^{+}\right)$and fewer apoptotic cells $\left(\mathrm{TUNEL}^{+}\right)$than did AdhIFN- $\beta$ treated-tumors. Treatment with AdhIFN- $\beta$ downregulated the expression of interleukin- 8 and vascular endothelial cell growth factor-A. Taken together, our data indicated that forced expression of human IFN- $\beta$ in human prostate cancer cells significantly inhibited their prostatic growth, which correlated with downregulation of angiogenic molecules and suggested that adenoviral vector-mediated IFN- $\beta$ gene therapy could be an effective approach for the management of human prostate cancer.
\end{abstract}

Correspondence to: Dr Zhongyun Dong, Department of Internal Medicine, Hematology-Oncology Division, University of Cincinnati College of Medicine, 3125 Eden Ave., Cincinnati, OH 45267, USA E-mail: dongzu@ucmail.uc.edu

Key words: interferon- $\beta$, prostate cancer, adenoviral vectors, angiogenesis

\section{Introduction}

Prostate cancer is the most common cancer and the second most common cause of cancer death among men in the United States (1). It was expected that 232,090 men would be diagnosed of and 30,350 men would die from this disease in 2005 (1). As cancer detection techniques improve, more patients are diagnosed with clinically localized disease, whereas the number of patients with disseminated disease is on the decline (2). Although most patients with clinically localized prostate cancer can be cured by radical prostatectomy or radiation therapy, a significant number of them $(\sim 30 \%)$ will develop local recurrence within the prostate, and some ultimately will develop disseminated disease (2). Therefore, more effective therapies that can cure localized tumors and prevent their metastasis are urgently needed.

IFN- $\beta$, a type I IFN, is a cytokine that can stimulate immune response, inhibit tumor cell growth, and induce cell differentiation and apoptosis (3-7). Moreover, compelling evidence indicates that IFN- $\beta$ is a potent anti-angiogenic and anti-metastatic molecule. Not only does IFN- $\beta$ inhibit the growth and migration of endothelial cells (8), as other angiogenic inhibitors do, but it also downregulates the expression of molecules that mediate angiogenesis and invasion in tumor cells $(9,10)$. Clinical trials using type I IFNs have shown a limited response for most solid tumors, possibly because of insufficient accumulation of biologically active IFN- $\beta$ within the tumors (11). Indeed, it has been shown that intralesional delivery of the IFN- $\beta$ gene, which allows for the accumulation of higher intratumoral concentrations of IFN- $\beta$, is able to suppress primary tumors and prolong the survival of tumorbearing mice (12-21). Moreover, IFN- $\beta$ gene therapy in immune-competent mice has been shown to induce systemic immune responses and confer tumor-specific immune protection against a second challenge $(14,20,22,23)$.

Our previous studies concluded that: i) human prostate cancer cells overexpressing murine IFN- $\beta$ lost their tumorigenicity and metastasis potential in mice (24); ii) intratumoral delivery of murine IFN- $\beta$ gene using an adenoviral vector inhibits progression of orthotopic tumors of human prostate cancer cells and significantly prolonged the survival of tumorbearing mice $(25,26)$; iii) murine IFN- $\beta$ gene therapy inhibits the growth of mouse prostatic tumors in immune-competent 
mice; and iv) murine IFN- $\beta$ mediates its inhibitory effects on tumor growth and metastasis by activation of macrophages and natural killer cells and by suppression of angiogenesis $(25,26)$. Because the action of IFN- $\beta$ is species-restricted $(27,28)$, we further investigated the effects of intratumoral delivery of the human IFN- $\beta$ gene on the orthotopic growth of human prostate cancer cells in the present study. We found that forced expression of human IFN- $\beta$ significantly inhibited prostatic tumor growth, which correlated with the downregulation of angiogenic molecules. These data strongly suggest that adenoviral vector-mediated IFN- $\beta$ gene therapy could be an alternative approach for management of human prostate cancer, especially locally advanced disease.

\section{Materials and methods}

Mice. Specific pathogen-free male athymic nude mice were purchased from Harlan Sprague-Dawley, Inc., Indianapolis, IN. Mice were maintained in a facility approved by the American Association for Accreditation of Laboratory Animal Care, and in accordance with current regulations and standards of the United States Department of Health and Human Services, and NIH. The mice were used according to institutional guidelines when they were 8-10 weeks of age.

Reagents. Eagle's minimal essential medium (MEM), $\mathrm{Ca}^{2+}$, $\mathrm{Mg}^{2+}$-free HBSS, and FBS were purchased from Hyclone (Logan, UT). RNA Later was from Ambion (Austin, TX). A TRIzol RNA extraction kit was purchased from Invitrogen (Carlsband, CA). Antibodies to PCNA and CD31 were purchased from BD Biosciences (San Jose, CA). Antibodies against IL-8 and VEGF were purchased from R\&D Systems (Minneapolis, MN) and Chemicon International (Temecula, CA), respectively. A TUNEL kit was purchased from Promega (Madison, WI). An enzyme-linked immunosorbent assay (ELISA) kit for human IFN-ß was obtained from Fujirebio Inc. (Tokyo, Japan). AdhIFN- $\beta$, an adenoviral vector encoding the human IFN- $\beta$ gene, and AdE/1, a control adenoviral vector with no expression cassette, were generously provided by Drs Colin Dinney and Bingliang Fang at the University of Texas M.D. Anderson Cancer Center, Houston, respectively. The adenoviral vectors were propagated in 293 cells and purified by the two-step $\mathrm{CsCl}_{2}$ gradient centrifugation protocol (29).

Tumor cell inoculation. The well-characterized metastatic PC-3MM2 human prostate carcinoma cell lines (24,30-32) were used. PC-3MM2 cells were maintained as a monolayer culture in MEM supplemented with 5\% FBS, non-essential amino acids, sodium pyruvate, vitamin $\mathrm{A}$, and glutamine. Cells in their exponential growth phase were harvested by a 1 -min treatment with a $0.25 \%$ trypsin- $0.02 \%$ EDTA solution, detached into MEM-10\% FBS. The cell suspension was agitated gently to produce a single-cell suspension and resuspended in HBSS. Only suspensions of single cell with viability exceeding $95 \%$ (ascertained by trypan-blue exclusion) were used in the studies.

Mice were anesthetized with Nembutal and placed in the supine position. The surgical procedure was performed as detailed in our previous study (26). Briefly, a lower midline incision was created and the prostate exposed. A tumor cell suspension $\left(10^{5}\right.$ cells in $20 \mu \mathrm{l}$ HBSS $)$ was injected into the dorsal prostatic lobes using a 30-gauge needle, a 1-ml disposable syringe, and a calibrated push button-controlled dispensing device (Hamilton Syringe Company, Reno, NV). The abdominal wound was closed in two layers with suture and wound clips (Autoclip; Clay Adama, Parsippany, NJ).

Treatment procedure. Mice were anesthetized with Nembutal, the incision reopened, and the prostate tumor exposed. PBS, AdE/ 1 , or AdhIFN- $\beta$ in $40 \mu 1$ of buffer was injected into the center of each tumor with a Hamilton syringe and a 30-gauge needle over $3 \mathrm{~min}$. The needle was removed slowly after a 30 -sec delay. Prostate tumors and lymph node metastases were determined at the end of the experiments (28-32 days after tumor cell inoculation). Primary tumors (including the entire prostate) were weighed when the experiments were terminated; regional lymph node metastasis was assessed by microscopic examination of H\&E-stained serial paraffin sections (26).

Immunohistochemical staining. Immunohistochemical analyses were performed as described previously $(24,26)$. Briefly, tumor tissues were placed in OCT compounds and snap frozen in liquid nitrogen. Frozen sections $(8-10 \mu \mathrm{m})$ were fixed in cold acetone and treated with $3 \%$ hydrogen peroxide $\left(\mathrm{H}_{2} \mathrm{O}_{2}\right)$ in methanol (v/v). The treated slides were incubated in blocking solution and then treated with antibody to CD31 (to assess tumor vascularity). The sections were rinsed and incubated with peroxidase-conjugated secondary antibodies. A positive reaction was visualized by incubating the slides with stable 3,3'-diaminobenzidine and counterstaining with Mayer's hematoxylin. For immunohistochemical staining using the antibodies to the proliferative cell nuclear antigen (PCNA), IL-8, and VEGF, paraffin sections of the tumor samples were dewaxed and stained as described for the frozen sections.

TUNEL assay. The TUNEL assay kit was used to identify apoptotic cells in tumor lesions following the manufacturer's instruction. Briefly, paraffin sections were dewaxed in xylene and rehydrated and then treated with $20 \mu \mathrm{g} / \mathrm{ml}$ proteinase $\mathrm{K}$ and incubated with $3 \% \mathrm{H}_{2} \mathrm{O}_{2}$ in methanol. The slides were incubated first in terminal deoxynucleotidyl transferase buffer, then with terminal deoxynucleotidyl transferase, and finally with a streptavidin-peroxidase conjugate and stained with 3amino-9-ethyl carbazole.

$R N A$ isolation and quantitative real-time reverse-transcriptional $P C R(q R T-P C R)$. After removal from mice, tumor tissues were treated with RNA Later, transferred into TRIzol at $100 \mathrm{mg}$ tissue/ml, homogenized using a Polytron homogenizer. Total tissue RNA was isolated following the manufacturer's instructions. Genomic DNA potentially present in the RNA samples was eliminated by treatment for $30 \mathrm{~min}$ at $37^{\circ} \mathrm{C}$ with $10 \mathrm{U}$ of RNase-free DNase I (Promega), followed by 5 -min heat inactivation at $95^{\circ} \mathrm{C}$. Two $\mu \mathrm{g}$ of total RNA was reversetranscribed in a $20 \mu 1$ reaction containing 200 units of reverse transcriptase (Stratagene, La Jolla, CA), 500 ng of Oligo d(T) primer, $500 \mathrm{nM} \mathrm{dNTP} \operatorname{mix}$, for $60 \mathrm{~min}$ at $42^{\circ} \mathrm{C}$, followed by 5 -min heat inactivation at $95^{\circ} \mathrm{C}$. Twenty-five ng of the obtained cDNA were amplified in a 7300 real-time PCR 

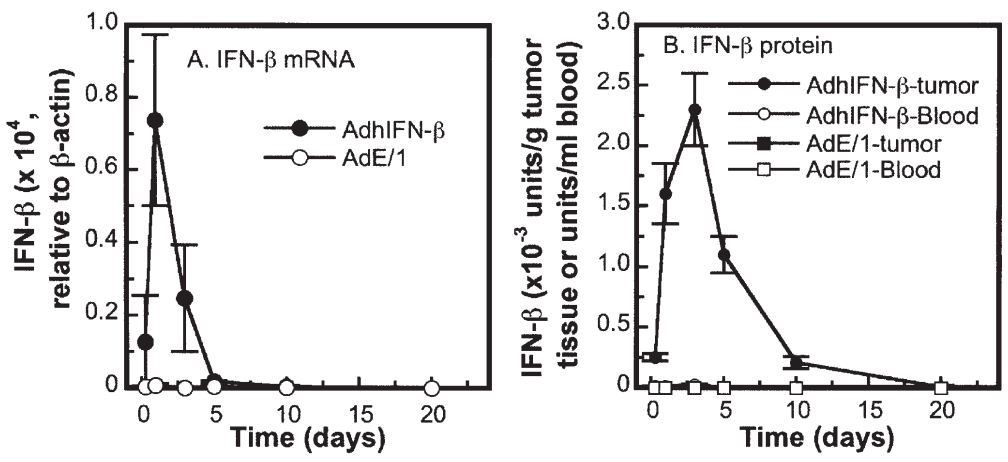

Figure 1. Adenoviral vector-mediated IFN- $\beta$ gene transfer in mice. PC-3MM2 cells were inoculated into the prostates of nude mice. Seven days later, the prostatic tumors were injected with $2 \times 10^{9} \mathrm{PFU}$ of either AdE/1 or AdhIFN- $\beta$. Expression of human IFN- $\beta$ mRNA (A) and protein (B) in the treated tumors was analyzed at various times after the injection by qRT-PCR and ELISA, respectively.

system (Applied Biosystems, Foster City, CA) in a reaction containing the primer pairs and the Brilliant SYBR-Green QPCR Master Mix (Stratagene). After an initial step at $95^{\circ} \mathrm{C}$ for $10 \mathrm{~min}$, temperature cycling was started (denaturation at $95^{\circ} \mathrm{C}$ for $30 \mathrm{sec}$, hybridization at $60^{\circ} \mathrm{C}$ for $30 \mathrm{sec}$, and elongation at $72^{\circ} \mathrm{C}$ for $30 \mathrm{sec}$ ) for 40 cycles. The cycle threshold values were used to calculate the normalized expression of target genes against $\beta$-actin using Q-Gene software (33).

Cell growth assay. PC-3MM2 cells were plated in triplicate at a density of $10^{3}$ cells/well in 96-well plates. Twenty-four hours later, adenoviral vectors or IFN- $\beta$ was added, and the plates were incubated for 4 days. During the final $2 \mathrm{~h}$ of incubation, 3-(4,5-dimethylthiazol-2-yl)-2,5-diphenyltetrazolium bromide (MTT, Sigma Chemicals, St. Louis, MO) was added at $0.42 \mathrm{mg} / \mathrm{ml}$. The medium was then removed, and dark-blue formazan was dissolved in dimethyl sulfoxide and the absorbance was measured with a FLUOstar Optima microplate reader at $570 \mathrm{~nm}$. The percentage of cell growth inhibition was calculated according to the following formula: growth inhibition $(\%)=(1-$ A570 of treated group/A570 of control group) x 100 .

ELISA. Fresh tumor samples were homogenized in PBS containing proteinase inhibitor cocktail (Roche Applied Science, Indianapolis, IN). Protein concentrations of the lysates were measured using a protein assay kit (Bio-Rad Laboratory, Hercules, CA). Human IFN- $\beta$ in the lysate was measured using an ELISA kit according to the manufacturer's instructions.

Statistical analysis. The gene therapy experiments were performed with 4-8 mice/group and were repeated at least once. Differences between treatment and control groups of tumor incidences and cell growth were analyzed with the t-test. Differences in tumor weight among groups were compared by ANOVA. Survival data were analyzed using the KaplanMeier plot, and their statistical significance was determined using the Mantel-Cox log-rank test.

\section{Results}

Efficiency of adenoviral vector-mediated gene transfer in prostatic tumors. In the first set of experiments, we evaluated the efficiency of adenovirus-mediated gene transduction in prostatic tumors. PC-3MM2 cells ( $10^{5} /$ mouse) were inoculated into the prostates of nude mice. On day 7 after the inoculation, tumors were injected with PBS or $2 \times 10^{9}$ PFU of AdLacZ. Three days later, frozen sections of tumor samples were stained to reveal AdLacZ-transduced cells. We found that $>80 \%$ of tumor cells in lesions injected with AdLacZ but not PBS expressed $\beta$-galactosidase (data not shown). Next, we determined the AdhIFN- $\beta$-induced expression of human IFN- $\beta$ in a similar setting. Tumors, injected with $2 \times 10^{9} \mathrm{PFU}$ of either AdE/ 1 or AdhIFN- $\beta$, were sampled at different times up to 20 days and IFN- $\beta$ mRNA and protein were analyzed by qRT-PCR and ELISA, respectively. Human IFN- $\beta$ mRNA was not detected in tumors injected with AdE/1 (Fig. 1A). In contrast, in AdhIFN- $\beta$-injected tumors, IFN- $\beta$ mRNA was detected at $8 \mathrm{~h}$, reached a peak on day 1 , decreased thereafter, and became undetectable 5 days later (Fig. 1A). IFN- $\beta$ protein was found only in tumors injected with AdhIFN-B, which was detected $8 \mathrm{~h}$ (125 units/g tumor tissue, $\sim 1 \mathrm{~cm}^{3}$ ) after the treatment and peaked on day $3(1,150 \mathrm{U} / \mathrm{g}$ tumor tissue). Intratumoral IFN- $\beta$ reduced to $110 \mathrm{U} / \mathrm{g}$ tumor tissue on day 10 and was not detected in samples collected on day 20 , respectively. Low levels of IFN- $\beta$, which followed the same kinetics as that in tumor lesions, were found in the blood of mice bearing tumors injected with AdhIFN- $\beta$, but not AdE/1. The highest concentration of IFN- $\beta$ in the blood was $23 \mathrm{U} / \mathrm{ml}$ on day 3 after intratumoral injection of AdhIFN- $\beta$. Taken together, our data show that intralesional injection of adenoviral vector efficiently transduced prostatic tumors.

Effects of AdhIFN- $\beta$ therapy on the growth and metastasis of orthotopic PC-3MM2 tumors. We next investigated the efficacy of adenovirus-mediated IFN- $\beta$ gene transfer in suppressing prostatic tumor progression. On day 7 after tumor cell inoculation, the lesions were injected with $\mathrm{PBS}$ or $2 \times 10^{9} \mathrm{PFU}$ of AdE/1 or AdhIFN-B. As shown in Fig. 2A, treatment with AdhIFN- 3 suppressed growth of PC-3MM2 tumors by up to $90 \%$. In contrast, injection with PBS or AdE/1 did not affect the growth of PC-3MM2 tumors (Fig. 2A). Regional lymph node metastases, identified on H\&E-stained slides (not shown), were observed in $100 \%$ of mice treated with PBS or AdE/1, and none of the mice treated with AdhIFN-B (Fig. 2A). We further determined the dose-dependent effects of AdhIFN- $\beta$ on the growth of orthotopic PC-3MM2 tumors. PC-3MM2 

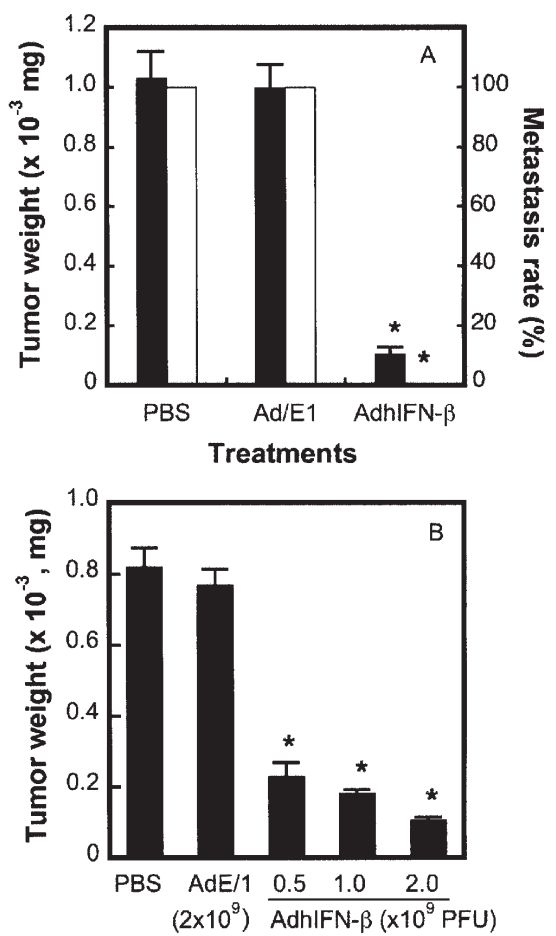

Treatment

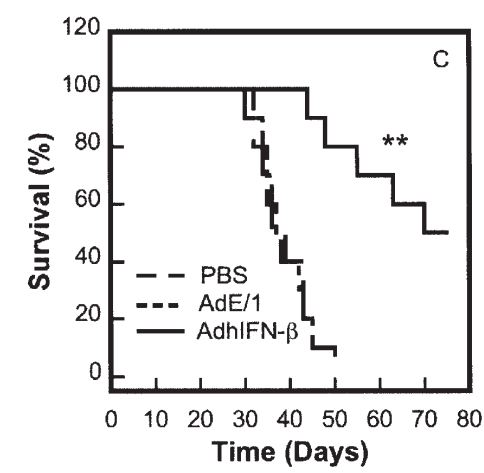

Figure 2. Therapeutic effects of AdhIFN- $\beta$ against orthotopic PC-3MM2 tumors. PC-3MM2 cells were inoculated into the prostates of nude mice. Seven days later, the tumors were injected with PBS or $2 \times 10^{9} \mathrm{PFU}$ of either AdE/1 or AdhIFN-B. Experiments were terminated 3 weeks after the therapy. Prostatic tumors were weighed and aortic lymph node metastases were determined on paraffin-embedded sections (A); solid bar, tumor weight; open bar, metastasis rate. On day 7 after tumor cell inoculation, tumors were injected with PBS, $2 \times 10^{9}$ of $\mathrm{AdE} / 1$, or different doses of AdhIFN-B. Experiments were terminated 3 weeks after the therapy and prostatic tumors were weighed (B). Seven days after tumor cell inoculation, the tumors were injected with PBS or $2 \times 10^{9}$ PFU of either PBS or AdhIFN- 3 . Mice were sacrificed when they were moribund and the survival times were recorded (C).

tumors, on day 7 after tumor cell inoculation, were injected with PBS, AdE/1, or increasing doses of AdhIFN-ß. Data in Fig. 2B show that AdhIFN-B inhibited tumor growth in a dosedependent manner: tumor growth was reduced by 72,78 , and $87 \%$ in mice injected with $0.5,1$, and $2 \times 10^{9}$ of AdhIFN- $\beta$, respectively. To determine whether AdhIFN- $\beta$ could improve the survival of tumor-bearing mice, tumors were injected with PBS or $2 \times 10^{9} \mathrm{PFU}$ of either AdE/ 1 or AdhIFN- 3 . Mice were sacrificed when they were moribund. The data in Fig. 2C show that therapy with AdhIFN- $\beta$ significantly prolonged the survival of tumor-bearing mice as compared to those injected with PBS or the control vector $(\mathrm{p}<0.01)$; median survival for mice treated with PBS, AdE/1, and AdhIFN- $\beta$ were 37, 38, and 70 days, respectively.

Effects of AdhIFN- $\beta$ therapy on cell growth and apoptosis in tumors. Cell replication and death are the two parameters that determine tumor growth rate. We, therefore, examined PCNA expression, which is expressed mainly in the late $\mathrm{G} 1$ and $\mathrm{M}$ phase of the cell cycle and indicates cell replication (34), by immunohistochemical staining and apoptosis by TUNEL staining, respectively. On day 5 after the intralesional injection of PBS or $2 \times 10^{9} \mathrm{PFU}$ of either AdE/ 1 or AdhIFN- $\beta$, tumors were sampled for in vitro analyses. As shown in Fig. 3, most cells $(>85 \%)$ in tumors injected with PBS (Fig. 3a) or AdE/1 (Fig. 3b) were stained strongly by the PCNA antibody and very few cells $(<0.1 \%)$ stained positively in the TUNEL assay (Fig. 3d and e). Although most cells (>50\%) in tumors injected with AdhIFN-B were also stained positively by the PCNAspecific antibody (Fig. 3c), both the intensity of the staining and the number of positively stained cells were significantly reduced in comparison with those in tumors injected with PBS or AdE/1. In contrast, the number of cells positively stained by the TUNEL assay increased by $\sim 3-5$-fold in tumors injected with AdhIFN-B (Fig. 3f) compared with that in PBS or AdE/ 1 treated tumors. Comparing the effects of AdhIFN- $\beta$ therapy on cell proliferation apoptosis, these data suggest that the suppression of tumor growth by AdhIFN- $\beta$ is due mainly to the reduction of tumor cell replication.

Tumor growth and metastasis require angiogenesis (35). Since IFN- $\beta$ is a potent angiogenesis inhibitor (8-10), we examined microvessels in the tumors by immunohistochemical staining using an antibody against CD31, which is expressed on microvessel endothelial cells. Interestingly, we did not observe significant differences in microvessel density among tumors injected with PBS (Fig. 3g), AdE/1 (Fig. 3h), and AdhIFN-B (Fig. 3i). IL-8 and VEGF-A are overexpressed in human prostate cancer, especially in advanced diseases (36-39). Overexpression of these two proangiogenic molecules is shown to be involved in angiogenesis and progression of PC-3 tumors in mice (40-43). We, therefore, determined the effects of AdhIFN- $\beta$ therapy on the expression of IL-8 and VEGF-A in orthotopic PC-3MM2 tumors. Data in Fig. 31 and o show that IL-8 and VEGF-A in tumors injected with AdhIFN- $\beta$ were significantly lower than in those injected with PBS (Fig. 3j and $\mathrm{m}$ ) or AdE/1 (Fig. 3k and n). We further analyzed the expression levels of IL-8 and VEGF-A during the course of the therapy by qRT-PCR. As shown in Fig. 4, the downregulation of both IL-8 (Fig. 4A) and VEGF-A (Fig. 4B) was detected 1 day after intratumoral injection of AdhIFN-B, reached its maximum on day 3 and lasted for up to 10 days.

Effects of AdhIFN- $\beta$ on cell growth and expression of IL-8 and VEGF-A. To investigate whether the therapeutic effects of AdhIFN-B correlate with its direct effects on cells and to exclude the possibility that the apparent downregulation of IL-8 and VEGF-A mRNA was an artifact caused by the contamination of mouse tissue RNA in the samples, we determined the effects of AdhIFN- $\beta$ on the growth and expression of IL-8 and VEGF-A in PC-3MM2 cells in cell culture. PC-3MM2 cells in a 96-well plate at 1,000 cells/well 


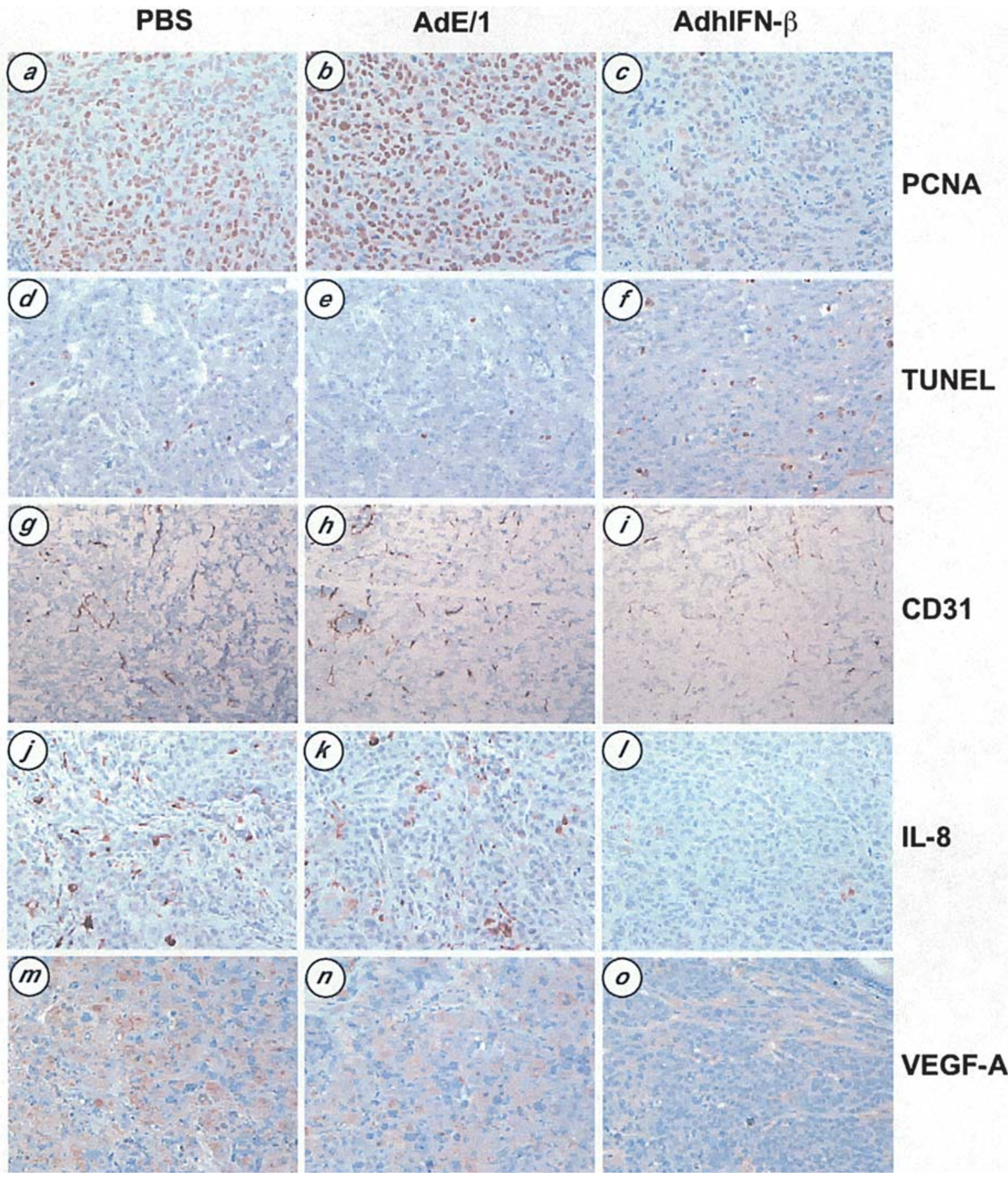

Figure 3. Immunohistochemical staining of tumors. PC-3MM2 tumors were inoculated into the prostates of mice. On day 7 after tumor cell inoculation, tumors were injected with PBS or $2 \times 10^{9}$ of either AdE/ 1 or AdhIFN- $\beta$. The treated tumors were sampled 5 days after the therapy for immunohistochemical staining or TUNEL assay.

were cultured for $96 \mathrm{~h}$ in normal medium or infected with $3 \times 10^{4}$ plaque-forming $\mathrm{U} / \mathrm{ml}$ of either AdE/1 or AdhIFN-B. Cells treated with $1,000 \mathrm{U} / \mathrm{ml}$ of recombinant human IFN- $\beta$ served as a positive control. As shown in Fig. 5A, the growth of PC-3MM2 cells was significantly inhibited by AdhIFN- $\beta$ and, to a less extent, by IFN- $\beta$, but not by the same concentration of AdE/1. Similarly, expression of both IL-8 (Fig. 5B) and VEGF-A (Fig. 5C) was downregulated by transduction of PC-3MM2 cells for $48 \mathrm{~h}$ with 30 multiplicity of infection (MOI) of AdhIFN- $\beta$ but not AdE/1. The expression of these two angiogenic molecules was also reduced by treatment with human IFN-B (Fig. 5B and C).

\section{Discussion}

Our previous studies have shown that intralesional delivery of the murine IFN- $\beta$ gene inhibits the growth of PC-3MM2 human prostate cancer cells implanted in the prostates of nude mice $(25,26)$. Because of the species-restricted action of IFN- $\beta$, we further investigated the effects of the adenovirusmediated transfer of the human IFN- $\beta$ gene on growth and angiogenesis in an orthotopic model of human prostate cancer. Our data show that the adenoviral vector efficiently transduced human prostate cancer cells in both cell culture and tumor lesions. After a single intratumoral injection of AdhIFN-B, 

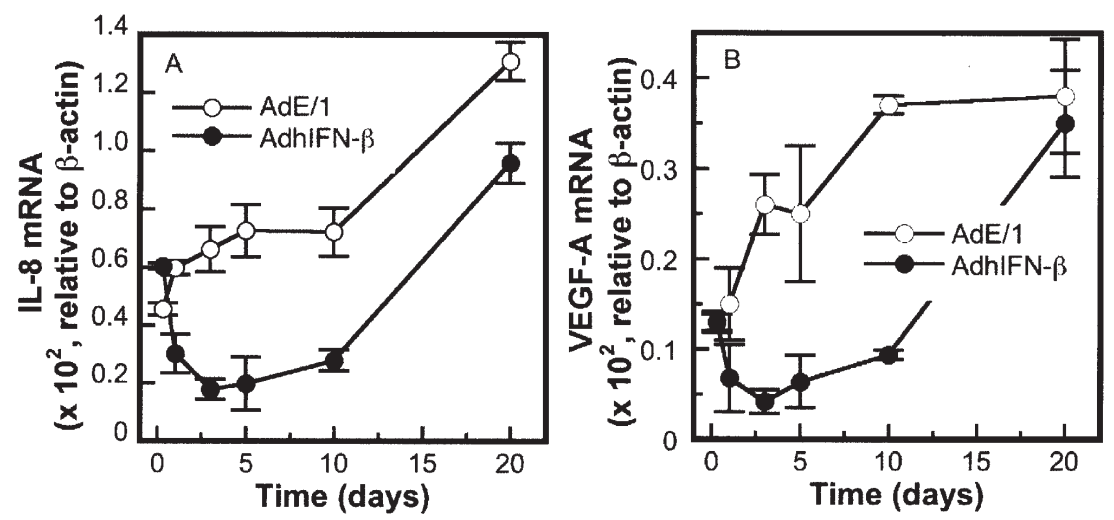

Figure 4. Expression of IL-8 and VEGF-A in PC-3MM2 tumors. PC-3MM2 cells were inoculated into the prostates of nude mice. Seven days later, the prostatic tumors were injected with $2 \times 10^{9} \mathrm{PFU}$ of either AdE/1 or AdhIFN-B. Expression of IL-8 (A) and VEGF-A (B) in the treated tumors was analyzed at various times after the injection by qRT-PCR.
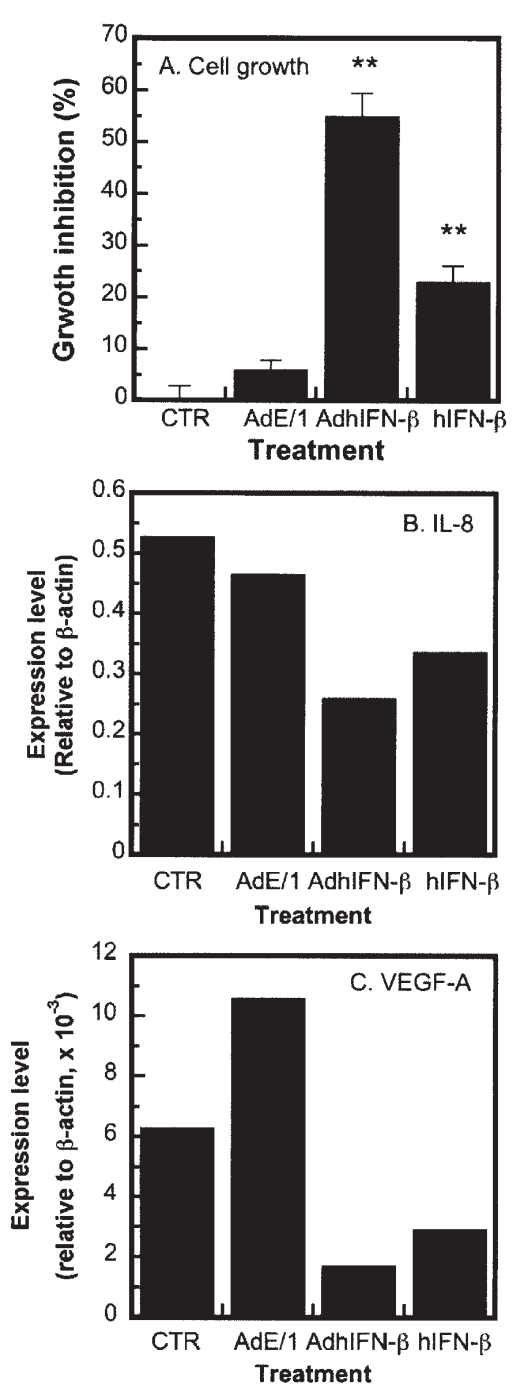

Figure 5. Effects of AdhIFN-B on cell growth and angiogenic molecule expression in culture. PC-3MM2 cells were plated into a 96-well plate at 1,000 cells/well and incubated for 4 days with adenoviral vectors or recombinant IFN- $\beta$. Viable cells in the wells were stained with MTT and the effects of the vectors or IFN- $\beta$ on cell growth were determined (A). PC-3MM2 cells were plated into $60-\mathrm{mm}$ plates at $10^{6} /$ plate and incubated for $48 \mathrm{~h}$ in $5 \%$ FBS-MEM or the medium containing 30 MOI of either AdE/1 or AdhIFN-B. Total cellular RNA was then extracted and the presence of IL-8 mRNA (B) and VEGF-A mRNA (C) was determined by qRT-PCR. human IFN- $\beta$ protein was detected in tumor lesions for up to 10 days. The intratumoral delivery of AdhIFN- $\beta$ significantly retarded tumor growth, prevented metastasis, and prolonged the survival of tumor-bearing mice.

Analyses of cell growth and apoptosis suggest that inhibition of tumor growth by AdhIFN-ß gene therapy is due mainly to the suppression of tumor cell replication. We based this conclusion on the following observations. First, AdhIFN-B injection significantly reduced cell replication in tumors revealed by PCNA staining. Second, AdhIFN- $\beta$ therapy only moderately enhanced apoptosis in tumors. Third, infection of cells in culture with AdhIFN- $B$ or treatment of cells with recombinant human IFN- $\beta$ significantly inhibited cell growth.

Intratumoral injection of AdhIFN- $\beta$ downregulated the expression of angiogenic molecules IL-8 and VEGF-A by PC-3MM2 cells both in mice and in tissue culture, suggesting that the therapy suppressed tumor angiogenesis. In contrast to the therapy against PC-3MM2 tumors using an adenoviral vector encoding the murine IFN- $\beta$ gene that leads to a reduction of microvessel density $(25,26)$, we did not observe significant alteration of the microvessel density in tumors treated by AdhIFN- $\beta$. This difference is very possibly caused by the species-restricted action of IFN- $\beta(27,28)$. Murine IFN- $\beta$ has no direct effects on PC-3MM2 cells (24). It activates host macrophages to express inducible nitric oxide synthase and, hence, to generate cytotoxic nitric oxide $(25,26)$. Therefore, a therapy using the murine IFN- $\beta$ gene induced apoptosis of endothelial cells, leading to a reduction of microvessel density, and massive tumor cell death in the lesions $(25,26)$. On the other hand, human IFN- $\beta$ has no direct effects on host cells in the tumor environment. It inhibits tumor cell replication and expression of angiogenic molecules by the tumor cells. Under these conditions, blood vessel formation, i.e., angiogenesis, is blocked, resulting in the retardation of tumor growth, but vessel density is not significantly altered. The significant reductions of cell replication and moderate increase in apoptosis observed in the present study also support this notion. Therefore, therapies against human prostate cancer in patients using an adenoviral vector encoding human IFN-B may suppress tumor growth by the following mechanisms: a) inhibition of angiogenesis as well as tumor cell replication as observed in the present study, b) microvesscular damage 
as reported in our previous studies $(25,26)$, and c) stimulation of host immune response $(14,20,22,23)$, and will produce much superior therapeutic effects than do using either murine or human IFN- $\beta$ genes in animal models of human prostate cancer cells.

In conclusion, we report that intratumoral delivery of an adenoviral vector encoding the human IFN- $\beta$ gene suppressed tumor growth and prolonged the survival of tumor-bearing mice, which correlated with the downregulation of the expression of IL-8 and VEGF-A. Together with our previous studies showing the therapeutic effects of murine IFN- $\beta$ gene against both human tumor cells in nude mice $(25,26)$ and mouse prostatic tumors in immune-competent mice (44), these data strongly support the notion that IFN-ß gene therapy could be an effective alternative therapy for locally advanced prostate cancer.

\section{Acknowledgments}

The authors would like to thank Dr Colin Dinney (University of Texas M.D. Anderson Cancer Center, UTMDACC, Houston, TX) for AdhIFN- $\beta$ and Dr Bingliang Fang (UTMDACC) for providing AdE/1 vectors, respectively. This work was supported in part by start-up funds from the University of Cincinnati College of Medicine Cancer Center (to S.L. and Z.D.) and grant RSG-98-332-02-CCE from the American Cancer Society (to Z.D.).

\section{References}

1. Jemal A, Murray T, Ward E, Samuels A, Tiwari RC, Ghafoor A, Feuer EJ and Thun MJ: Cancer statistics, 2005. CA Cancer J Clin 55: 10-30, 2005.

2. Steele GS and Richie JP: Management of local failure following treatment of localized prostate cancer. In: Advanced Therapy of Prostate Disease. Resnick MI and Thompson IM (eds). B.C. Decker Inc., Hamilton, Ontario, pp365-377, 2000.

3. Lokshin A, Mayotte JE and Levitt ML: Mechanism of interferon beta-induced squamous differentiation and programmed cell death in human non-small-cell lung cancer cell lines. J Natl Cancer Inst 87: 206-212, 1995.

4. Belhumeur P, Lanoix J, Blais Y, Forget D, Steyaert A and Skup D: Action of spontaneously produced beta interferon in differentiation of embryonal carcinoma cells through an autoinduction mechanism. Mol Cell Biol 13: 2846-2857, 1993.

5. Qin XQ, Runkel L, Deck C, De Dios C and Barsoum J: Interferonbeta induces $\mathrm{S}$ phase accumulation selectively in human transformed cells. J Interferon Cytokine Res 17: 355-367, 1997.

6. Clemens MJ: Interferons and apoptosis. J Interferon Cytokine Res 23: 277-292, 2003.

7. Biron CA: Interferons alpha and beta as immune regulators - a new look. Immunity 14: 661-664, 2001.

8. Albini A, Marchisone C, Del Grosso F, Benelli R, Masiello L, Tacchetti C, Bono M, Ferrantini M, Rozera C, Truini M, Belardelli F, Santi L and Noonan DM: Inhibition of angiogenesis and vascular tumor growth by interferon-producing cells: a gene therapy approach. Am J Pathol 156: 1381-1393, 2000.

9. Singh RK, Gutman M, Bucana CD, Sanchez R, Llansa N and Fidler IJ: Interferons alpha and beta down-regulate the expression of basic fibroblast growth factor in human carcinomas. Proc Natl Acad Sci USA 92: 4562-4566, 1995.

10. Yamamoto S, Yasui W, Kitadai Y, Yokozaki H, Haruma K, Kajiyama G and Tahara E: Expression of vascular endothelial growth factor in human gastric carcinomas. Pathol Int 48: 499-506, 1998

11. Einhorn S and Grander D: Why do so many cancer patients fail to respond to interferon therapy? J Interferon Cytokine Res 16: 275-281, 1996.

12. Ferrantini $\mathrm{M}$ and Belardelli F: Gene therapy of cancer with interferon: lessons from tumor models and perspectives for clinical applications. Semin Cancer Biol 10: 145-157, 2000.
13. Alizadeh H, Howard K, Mellon J, Mayhew E, Rusciano D and Niederkorn JY: Reduction of liver metastasis of intraocular melanoma by interferon-beta gene transfer. Invest Ophthalmol Vis Sci 44: 3042-3051, 2003.

14. Odaka M, Sterman DH, Wiewrodt R, Zhang Y, Kiefer M, Amin KM, Gao GP, Wilson JM, Barsoum J, Kaiser LR and Albelda SM: Eradication of intraperitoneal and distant tumor by adenovirus-mediated interferon-beta gene therapy is attributable to induction of systemic immunity. Cancer Res 61: 6201-6212, 2001.

15. Kruklitis RJ, Singhal S, Delong P, Kapoor V, Sterman DH, Kaiser LR and Albelda SM: Immuno-gene therapy with interferon-beta before surgical debulking delays recurrence and improves survival in a murine model of malignant mesothelioma. J Thorac Cardiovasc Surg 127: 123-130, 2004.

16. Kobayashi N, Kuramoto T, Chen S, Watanabe Y and Takakura Y: Therapeutic effect of intravenous interferon gene delivery with naked plasmid DNA in murine metastasis models. Mol Ther 6: 737-744, 2002.

17. Hendren SK, Prabakaran I, Buerk DG, Karakousis G, Feldman M, Spitz F, Menon C and Fraker DL: Interferon-beta gene therapy improves survival in an immunocompetent mouse model of carcinomatosis. Surgery 135: 427-436, 2004.

18. Streck CJ, Ng CY, Zhang Y, Zhou J, Nathwani AC and Davidoff AM: Interferon-mediated anti-angiogenic therapy for neuroblastoma. Cancer Lett 228: 163-170, 2005.

19. Streck CJ, Zhang Y, Miyamoto R, Zhou J, Ng CY, Nathwani AC and Davidoff AM: Restriction of neuroblastoma angiogenesis and growth by interferon-alpha/beta. Surgery 136: 183-189, 2004.

20. Lu W, Fidler IJ and Dong Z: Eradication of primary murine fibrosarcomas and induction of systemic immunity by adenovirusmediated interferon beta gene therapy. Cancer Res 59: 5202-5208, 1999.

21. Lu W, Su J, Kim LS, Bucana CD, Donawho C, He J, Fidler IJ and Dong Z: Active specific immunotherapy against occult brain metastasis. Cancer Res 63: 1345-1350, 2003.

22. Odaka M, Wiewrodt R, De Long P, Tanaka T, Zhang Y, Kaiser L and Albelda S: Analysis of the immunologic response generated by Ad.IFN-beta during successful intraperitoneal tumor gene therapy. Mol Ther 6: 210-218, 2002.

23. Natsume A, Mizuno M, Ryuke Y and Yoshida J: Antitumor effect and cellular immunity activation by murine interferonbeta gene transfer against intracerebral glioma in mouse. Gene Ther 6: 1626-1633, 1999.

24. Dong Z, Greene G, Pettaway C, Dinney CP, Eue I, Lu W, Bucana CD, Balbay MD, Bielenberg D and Fidler IJ: Suppression of angiogenesis, tumorigenicity, and metastasis by human prostate cancer cells engineered to produce interferon-beta. Cancer Res 59: 872-879, 1999.

25. Zhang F, Lu W and Dong Z: Tumor-infiltrating macrophages are involved in suppressing growth and metastasis of human prostate cancer cells by INF-beta gene therapy in nude mice. Clin Cancer Res 8: 2942-2451, 2002.

26. Cao G, Su J, Lu W, Zhang F, Marteralli D, Zhao G and Dong Z: Adenovirus-mediated interferon-beta gene therapy suppresses growth and metastasis of human prostate cancer in nude mice. Cancer Gene Ther 8: 497-505, 2001.

27. Constantinescu SN, Croze E, Wang C, Murti A, Basu L, Mullersman JE and Pfeffer LM: Role of interferon alpha/beta receptor chain 1 in the structure and transmembrane signaling of the interferon alpha/beta receptor complex. Proc Natl Acad Sci USA 91: 9602-9606, 1994.

28. Keay S and Grossberg SE: Interferon inhibits the conversion of 3T3-L1 mouse fibroblasts into adipocytes. Proc Natl Acad Sci USA 77: 4099-4103, 1980.

29. Graham FL and Prevec L: Manipulation of adenovirus vectors. In: Gene Transfer and Expression Protocols. Murray EJ (ed). Humana Press, NJ, pp109-128, 1991.

30. Kozlowski JM, Fidler IJ, Campbell D, Xu ZL, Kaighn ME and Hart IR: Metastatic behavior of human tumor cell lines grown in the nude mouse. Cancer Res 44: 3522-3529, 1984.

31. Stephenson RA, Dinney CP, Gohji K, Ordonez NG, Killion JJ and Fidler IJ: Metastatic model for human prostate cancer using orthotopic implantation in nude mice. J Natl Cancer Inst 84: 951-957, 1992.

32. Greene GF, Kitadai Y, Pettaway CA, von Eschenbach AC, Bucana CD and Fidler IJ: Correlation of metastasis-related gene expression with metastatic potential in human prostate carcinoma cells implanted in nude mice using an in situ messenger RNA hybridization technique. Am J Pathol 150: 1571-1582, 1997. 
33. Simon P: Q-gene: processing quantitative real-time RT-PCR data. Bioinformatics 19: 1439-1440, 2003.

34. Wilson GD, Camplejohn RS, Martindale CA, Brock A, Lane DP and Barnes DM: Flow cytometric characterisation of proliferating cell nuclear antigen using the monoclonal antibody PC10. Eur J Cancer 12: 2010-2017, 1992.

35. Folkman J: The role of angiogenesis in tumor growth. Semin Cancer Biol 3: 65-71, 1992.

36. Balbay MD, Pettaway CA, Kuniyasu H, Inoue K, Ramirez E, Li E, Fidler IJ and Dinney CP: Highly metastatic human prostate cancer growing within the prostate of athymic mice overexpresses vascular endothelial growth factor. Clin Cancer Res 5: 783-789, 1999.

37. Uehara H, Troncoso P, Johnston D, Bucana CD, Dinney C, Dong Z, Fidler IJ and Pettaway CA: Expression of interleukin-8 gene in radical prostatectomy specimens is associated with advanced pathologic stage. Prostate 64: 40-49, 2005.

38. Murphy C, McGurk M, Pettigrew J, Santinelli A, Mazzucchelli R, Johnston PG, Montironi R and Waugh DJ: Nonapical and cytoplasmic expression of interleukin-8, CXCR1, and CXCR2 correlates with cell proliferation and microvessel density in prostate cancer. Clin Cancer Res 11: 4117-4127, 2005.

39. Ferrer FA, Miller LJ, Andrawis RI, Kurtzman SH, Albertsen PC, Laudone VP and Kreutzer DL: Angiogenesis and prostate cancer: in vivo and in vitro expression of angiogenesis factors by prostate cancer cells. Urology 51: 161-167, 1998.
40. Zhang F, Lee J, Lu S, Pettaway CA and Dong Z: Blockade of transforming growth factor-beta signaling suppresses progression of androgen-independent human prostate cancer in nude mice. Clin Cancer Res 11: 4512-4520, 2005.

41. Moore BB, Arenberg DA, Stoy K, Morgan T, Addison CL, Morris SB, Glass M, Wilke C, Xue YY, Sitterding S, Kunkel SL, Burdick MD and Strieter RM: Distinct CXC chemokines mediate tumorigenicity of prostate cancer cells. Am J Pathol 154: 1503-1512, 1999.

42. Kitagawa Y, Dai J, Zhang J, Keller JM, Nor J, Yao Z and Keller ET: Vascular endothelial growth factor contributes to prostate cancer-mediated osteoblastic activity. Cancer Res 65: 10921-10929, 2005.

43. Liu XH, Kirschenbaum A, Yao S, Stearns ME, Holland JF, Claffey K and Levine AC: Upregulation of vascular endothelial growth factor by cobalt chloride-simulated hypoxia is mediated by persistent induction of cyclooxygenase-2 in a metastatic human prostate cancer cell line. Clin Exp Metastasis 17: 687-694, 1999.

44. Olson MV, Lee J, Zhang F, Wang A and Dong Z: Inducible nitric oxide synthase activity is essential for inhibition of prostatic tumor growth by interferon-beta gene therapy. Cancer Gene Ther 13: 676-685, 2006. 